\title{
Entrevista
}

\section{Exposição Além de Pompeia - redescobrindo os encantos de Stabiae}

A exposição foi realizada no período de 14 de setembro a 18 de novembro de 2012, de terça a sexta-feira, das $10 \mathrm{~h}$ às $20 \mathrm{~h}$, e aos sábados, domingos e feriados, das 15 às $18 \mathrm{~h}$ no Teatro Odylo Costa, filho da UERJ — Maracanã.

Qual foi a principal motivação para a realização da exposição Além de Pompeia - redescobrindo os encantos de Stabiae?

A principal motivação foi reencontrar e redescobrir a antiga relação entre a Itália, em particular Nápoles, com o Brasil. Entre o reino de Nápoles e o Brasil existiu uma imensa atividade de ligação histórica e cultural, que teve a sua coroação com o casamento entre Teresa Cristina de Bourbon e Dom Pedro II de Bragança.

\section{Quais foram os principais desafios enfrentados para trazer ao Brasil as obras artísticas expostas no Teatro Odylo Costa Filho da UERJ durante o evento?}

Trazer para uma outra nação obras originais é difícil; sendo antigas, se torna ainda mais difícil, porque é necessária não somente uma autorização da Superintendência Arqueológica, mas uma autorização do Ministério dos Bens Culturais. Pode-se imaginar a complexidade e o tempo para obter tais autorizações. Além disso, é necessário haver a garantia que um transporte tão longo não cause alterações a essas obras tão importantes e exclusivas.

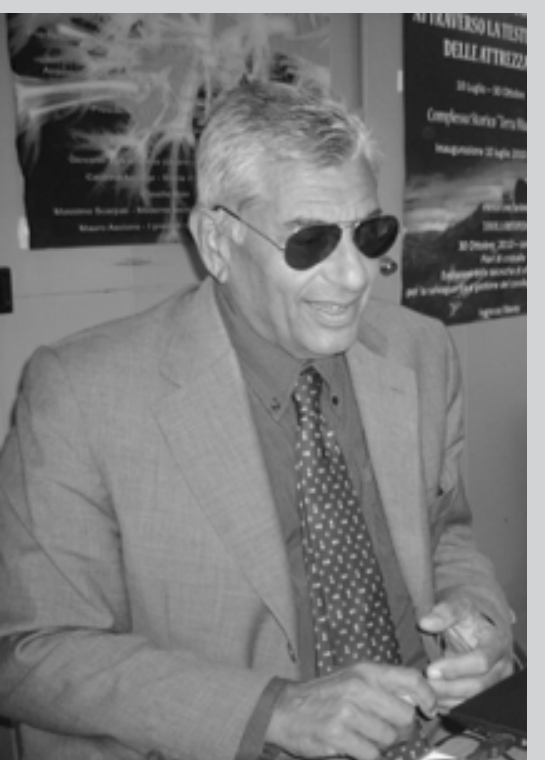

Dr. Ugo Di Capua, diretor do Departamento de Arqueologia Subaquática da Fundação RAS-Restoring Ancient Stabiae/direttore del Dipartimento di Archeologia Subacquea Fondazione Restoring Ancient Stabiae-RAS

Quantas peças foram expostas? O Sr. destacaria alguma delas? Qual?

As obras originais a serem expostas foram 28 e vão desde importantes pinturas, estátuas até uten- 
sílios da vida quotidiana. Certamente, se destaca entre as demais, o "quarto erótico", não pelo título que, por si só já é muito intrigante, mas porque representa uma peça de alta qualidade artística. As três paredes do quarto são completamente decoradas e o fundo negro torna todas as pinturas ainda mais evidentes e belas, seja do ponto de vista cromático ou artístico.

Qual a função dos monitores na exposição? Foi difícil treinar os alunos da Unati da UERJ para exercer essa função? Quais foram, na sua avaliação, os benefícios, para esses idosos, do treinamento recebido para atuar como monitores na exposição?

É uma bela realidade que esses alunos tenham adquirido uma cultura arqueológica clássica, de ótima qualidade, em tão pouco tempo. Tudo isso aconteceu por dois motivos: primeiro, porque estiveram na Itália, no Instituto Vesuviano, e "caíram" no coração da cultura clássica; segundo, é que a formação deles foi confiada à Luciana Jacobelli, arqueóloga de fama internacional e professora da Universidade de Molise. Outra coisa muito importante, o "arremesso" desse grupo em direção a essa nova e desafiadora disciplina, devido ao suporte dos professores Celia Caldas e Marcello Sottratti. Eu os vi na exposição atuando como guias junto aos visitantes e posso dizer que a comunicação deles é perfeita, seja do ponto de vista dos conteúdos, seja do ponto de vista da verdadeira e própria comunicação, porque era muito "emocional"; desta forma, esses estudantes envolvem os visitantes no clima da mostra!

\section{E para a população fluminense, qual é a grande contribuição da exposição?}

Certamente, a mostra oferece a oportunidade de ver de perto, verdadeiramente, essas peças que representam uma parte da cultura clássica, tão antiga e bela. Portanto, essa exposição pode ser considerada um ponto de partida para gerar na população fluminense um estímulo a conhecer diretamente este mundo que influenciou com a sua história até países distantes como o Brasil. Testemunho direto disso é a forte ligação que sempre existiu entre o Brasil e Nápoles.
Haverá algum desdobramento da exposição em termos de ações de pesquisa, ensino ou extensão realizadas por discentes e docentes da UERJ na Fundação RAS (por exemplo, estágios, realização de pesquisas em parceria com os pesquisadores da fundação, cursos de extensão ministrados no Brasil ou na Itália, etc.)? Se sim, de que tipo?

A mostra representa não só o contato com o Brasil, mas com a UERJ, e foi o primeiro fruto dessa parceria iniciada com nossa Fundação Restoring Anciet Stabiae, porque não estamos habituados a concretizar imediatamente as nossas relações institucionais. De fato, dos contínuos encontros com o reitor da UERJ e a Sub-Reitora da SR3, mas também com os outros Sub-Reitores da SR1 e SR2 foram feitos muitos caminhos para tornar a UERJ sempre mais competitiva na formação e na inovação. Certamente serão programados cursos de extensão nos setores de Turismo, de Arqueologia e Restauração e Oceanografia. Esses cursos começarão na Itália e se complementarão no Brasil. Gostaria de lembrar e jamais esquecer de agradecer ao reitor Ricardo Vieiralves de Castro, que acreditou em nós, porque a UERJ será a primeira Universidade do Brasil, a realizar uma "filiação" na Itália, em nosso Campus, Instituto Vesuviano, concretizando ainda uma volta "à política do fazer acontecer".

\section{Ao término da exposição, o material retorna à Itália ou serão feitas outras exposições no Brasil?}

$\mathrm{Na}$ realidade, foram feitas demandas em outros estados do Brasil, mas essa mostra certamente irá para Rússia, porque, com as suas universidades, é uma outra nação que mantém importante parceria com a nossa instituição.

Versão da entrevista em italiano

Qual è stata la motivazione principale per la mostra Alem de Pompeia riscoprendo il fascino di Stabiae?

La principale motivazione è stata quella di ritrovare e riscoprire l'antico legame tra l'Italia, ed in parti- 
colare di Napoli, con il Brasile. Tra il Regno di Napoli ed il Brasile ci fù una intensa attività di collegamento storico, commerciale, culturale, che ebbe il suo coronamento con il matrimonio tra Teresa Cristina di Borbone e don Pedro II di Braganza.

Quali sono state le principali sfide per portare in Brasile le opere esposte al Teatro Odylo Costa Filho UERJ durante I'evento?

Portare in altra Nazione opere originali è difficile, antiche lo è ancora di più, perchè è richiesta non solo l'autorizzazione della Soprintendenza Archeologica, ma l'autorizzazione del Ministero dei Beni Culturali. Si può ben capire la complessità ed il tempo per ottenere tali autorizzazioni. Inoltre è necessario avere la garanzia che un trasporto così lungo, non crei alterazioni a tali importanti ed esclusive opere.

\section{Quanti pezzi saranno esposti? Mr.} evidenziare qualcuno di loro? Cosa?

Le opere originali esposte sono 28 , e vanno da importanti affreschi murari, ad una statua, ad un'arula sino ad utensili di vita quotidiana. Sicuramente la "camera erotica", non per l'argomento che, di per se, è già molto intrigante, ma perchè rappresenta un pezzo di alta qualità artistica; le tre pareti della camera sono completamente decorate e lo sfondo nero, rende tutte le pitture ancora più evidenti e belle, sia dal punto di vista cromatico che artistico.

Quale sarà il ruolo di monitor in mostra? $E$ 'stato difficile per la formazione di studenti Unati UERJ per svolgere questa funzione? Quali sono stati, nella tua valutazione, $i$ benefici per questi anziani, hanno ricevuto una formazione ad agire come monitor in mostra?

É una bella realtà, che questi alunni abbiano acquisito una cultura archeologica classica in così poco tempo e per giunta di buona qualità. Tutto ciò è avvenuto per due motivi, il primo perchè sono venuti in Italia, presso il Vesuvian Institute, e si sono "calati" nel cuore della cultura classica, il secondo motivo e che la loro formazione fu affi- data a Luciana Jacobelli, archeologa di fama internazionale e docente presso l'Università $\mathrm{dl} \mathrm{Mo}$ lise. Altra cosa molto importante lo "slancio" di questo gruppo verso questa nuova ed impegnativa disciplina, perchè ben sostenuto dai docenti Celia Caldas e Marcello Sottratti. Ho sentito all'opera questi "studenti"con i visitatori e posso ben dire, che la loro comunicazione è perfetta, sia dal punto di vista dei contenuti, che dal punto di vista della vera e propria comunicazione, perchè essa era molto "emozionale", perciò questi studenti "calavano" subito i visitatori nel clima della mostra!

\section{E per il popolo dello Stato, che è il grande contributo di esposizione?}

Sicuramente la mostra offre l'opportunita di vedere da vicino, dal vero, questi pezzi che rappresentano uno spaccato della cultura classica, tanto antica e tanto bella, pertanto, questa esposizione si può considerare un punto di partenza, per generare nella popolazione "Fluminense" uno stimolo a conoscere direttamente questo mondo, che ha influensato con la sua storia, anche paesi lontani come il Brasile. Testimonianza diretta di ciò, è il forte collegamento che si è sempre avuto tra il Brasile e Napoli.

Ci sarà qualche ramo di esposizione in termini di attività di ricerca, di insegnamento o estensione fatta da studenti e insegnanti nel RAS UERJ Fondazione (ad esempio, stage, conducendo una ricerca in collaborazione con i ricercatori della fondazione, corsi di estensione insegnato in Brasile o Italia, ecc.)? Se sì, di che tipo?

La mostra è stato il contatto non solo con il Brasile ma con l' UERJ ed è stato il primo frutto di questo partnariato avviato con la nostra Fondazione Restoring Ancient Stabiae, perchè noi siamo abituati a concretizzare subito i nostri rapporti istituzionali; infatti dai continui incontri con il Rettore dell'UERJ e la sub Rettora dell'SR3, ma in verità anche con le altri sub Rettore dell'SR1 ed SR2, si stanno aprendo molte strade per rendere l'UERJ sempre più competitiva nella formazione e nell'innovazione. Facendo seguito a quanto detto, sicuramente saranno programmati 
corsi di estençao nei settori del Turismo culturale, dell'Archeologia e Restauro e della Scienza del Mare, questi si avvieranno in Italia e si completeranno in Brasile. Voglio ricordare e con questo non mi stancherò mai di ringraziar il Rettore,Ricardo Vieiralves de Castro, che ha creduto in noi, perchè l'UERJ, sarà laprima Università del Brasile, che ha realizzato una "filiazione" in Italia, presso il nostro Campus, Vesuvian Institute, concretizzando ancora una volta "la politica del fare".

\section{Al termine della mostra, il materiale torna in Italia o altre mostre saranno effettuati in Brasile?}

In verità ci sono state altre richieste in altri Stati del Brasile, ma questa Mostra, quasi sicuramente, andrà in Russia, perchè con le sue Università è un altra Nazione nostra importante partner.

Tradução feita por Carla Mariana Grassia Pastore, Licenciada em Letras Português-Italiano pela Universidade Federal do Rio de Janeiro. 